TITLE:

$<$ Notes> Sampling Rapidly

Dwindling Chimpanzee

Populations

AUTHOR(S):

Gagneux, Pascal

CITATION:

Gagneux, Pascal. < Notes> Sampling Rapidly Dwindling Chimpanzee Populations. Pan Africa News 1997, 4(2): 12-15

ISSUE DATE:

1997-12

URL:

http://hdl.handle.net/2433/143357

RIGHT:

Copyright (C) Pan Africa News. 


\title{
<NOTES>
}

\section{Sampling Rapidly Dwindling Chimpanzee Populations}

\author{
Pascal Gagneux \\ Biology Department, \\ University of Califormia San Diego \\ gagneux@biomail.ucsd.edu
}

In the course of an on-going study of the population genetics of west African chimpanzees $(1,2,3)$ we collected samples of wild chimpanzee populations in west Africa. We sampled shed hair collected from night nests which chimpanzees build in a new location at the end of each day. The hair-root cells of those shed hair contain DNA which can be analyzed using the Polymerase Chain Reaction (PCR). This method uses a heat-stable enzyme found in microorganisms living in natural hot springs, and allows researchers to obtain large numbers of identical copies of selected short stretches of the original DNA of a study organism (markers). Researchers can now study the genetics of wild animals non invasively by extracting DNA from shed hair, feces, chewed pieces of food and even museum skins $(4,5,6)$.

Visiting many different chimpanzee habitats has made the author very pessimistic about the survival chances of our closest living relative in west Africa. Marchesi et. al. (7) conducted a survey of chimpanzee populations of Côte d'Ivoire in 1991. Based on their findings, we visited a subset of the census sites in 1993-94 
and again in 1995 (13 different sites). We found chimpanzees at each of the sites within two days. We also found massive evidence of hunting at every site. Our local guides were always villagers, usually hunters, all of whom readily admitted having hunted chimpanzees. We were shocked by the amount of hunting we witnessed, even inside the National Parks. In two of them (Taï and Comoé National Park) we had to hide from poachers on three different occasions. Denis Lia, the African assistant who had participated in the 1991 census with the Marchesis was very impressed by how much lower the density of chimpanzee nests was compared to three years earlier when he had helped conducting the survey. Richard Barmes, who just returned from doing an elephant survey in the Marahoue National Park, central Côte d'Ivoire, did not see a single chimpanzee nest, where the Marchesis had found the highest density of nests in the course of their census only six years earlier (Barnes pers. com.). Even in Western Mali, in the Fauna Reserve of Bafing, where Moore (8) had conducted chimpanzee surveys and had reported that chimpanzees were unlikely to be hunted, because the Muslim faith of most inhabitants prohibits the consumption of primate meat, we found three local hunters who admitted having killed chimpanzees for food recently. One dramatic occurrence in the coastal forests of south-western Côte dTvoire, illustrates the situation well: sitting in a day-old chimpanzee nest the author could see villagers slashing and burning the forest on one side and hear buses drive by at high speeds on the newly paved coastal road on the other side. The same road which allows hunters to market their bush meat in the capital as it is now only four hours away. Because chimpanzees tend to be very noisy during daily bouts of social excitement, they make a very easy target for hunters who can readily find them. When their numbers are decimated to just a few individuals they are likely to remain silent and may survive for many years even in heavily disturbed habitat. The presence of such relic populations can easily give the illusion of "populations" of chimpanzees still remaining in an area.

Thus, while sampling chimpanzees appears to be relatively easy, if one has information on their distribution, the strong pressure exerted on chimpanzee populations by humans, directly by hunting, or indirectly by habitat destruction will most likely destroy the remaining wild chimpanzee populations in west Africa. Even if the habitat becomes very well protected, unless there is a rigorous enforcement of wildlife protection, i.e. a total ban of hunting, and regular enforcement on site, chimpanzees and most other large mammals will be shot out of even the most consistently protected forests. Recent surveys in the Tai National Park have shown that the presence of long-term research sites is the most efficient way of limiting poaching, as in the case of the Tai chimpanzee project. However, even the regular presence of field researchers is no safeguard against continuous low intensity hunting pressure. The proximity of natural chimpanzee populations to cacao and other fields leads to crop-raiding by the chimpanzees. Many of them are killed by farmers who are protecting their crops. In the course of our sampling trips we saw several cacao plantations located within official forest reserves. When political instability forces researchers to temporarily abandon their research sites, the study populations instantly become highly vulnerable because of their habituation.

Currently, population genetic studies such as ours run the danger of becoming "instant paleontology". After just a few years we are now in the possession of samples belonging to extinct regional populations. Several researchers have sampled and are still sampling natural chimpanzee populations. Jim Moore and Phillip Morin (9) sampled in Mali and Tanzania, Rosalind Alp has provided samples from one community in Tenkere, Sierra Leone, Tony Goldberg (10) and Babette Fahey have sampled chimpanzees in Uganda and Zaire, Anne Pusey and her colleagues are sampling in Gombe, Katie Gonder (11) is currently sampling in Nigeria and Cameroun. Very little remains known on the distribution and the population genetics of central African chimpanzees in Cameroun, Gabon, CAR and Zaire. These regions are known for their people's traditional fondness for bush meat. War and political instability only contribute to the desperate need to find cheap animal protein or sources for cash (bush meat as a cash crop).

Recently, a Population and Habitat Viability Assessment (PHVA) project has been proposed for west. African chimpanzees. The idea is to bring together African and Non-African specialists, wildlife managers and conservationists in order to design an action plan for the conservation of west African chimpanzees. A PHVA meeting organized by the Conservation Breeding Specialist Group (CBSG) in Uganda early this year has proved rather successful. Unlike the situation in Uganda, however, most west African Nations have long-lasting traditions of bush meat consumption. The issue of bush meat cannot be resolved by moralizing attitudes held by activists from industrial nations. Rather, we need culturally sensitive approaches to the problem. 
The importance of primate hunting and consumption for human food and the transfer of dangerous infectious diseases has become increasingly clear in recent years. Between 1994 and 1996 there were three independent Ebola outbreaks in Gabon, all of which were associated with hunters and the deaths of non human primates (12). The WHO in collaboration with several other organizations is currently conducting a search for the natural reservoir species of the Ebola virus in the Tai National Park, Côte d'Tvoire. The death of several habituated chimpanzees there in 1992 and 1994, and the subsequent infection of a Swiss researchers have alerted the medical community. Even though some may advocate using the fact that killing chimpanzees can infect people with Ebola and/or possibly SIV/HIV as a propaganda tool against the consumption of primates, one needs to be cautious, for such information could easily backfire. People could all too suddenly decide that killing as many chimpanzees as possible is a way of getting rid of dangerous diseases.

Pleading for the protection of chimpanzees based on the fact that they are our close relatives seems rather futile considering the lack of compassion that we regularly show even towards our fellow humans. There are utilitarian arguments for the conservation of chimpanzees: Studies of natural chimpanzee communities across Africa have profoundly changed our views on human nature and human evolution. Chimpanzees have great potential value for attracting ecotourism. The medicinal use of forest plants by chimpanzees as documented by Huffman and others(13), promises to reveal new drugs based on pharmaceutical compounds found in such plants. Finally, there is the fact that chimpanzees in their natural habitat may harbor the solution to several medical problems of global importance. The very different ways in which our closest living relative is coping with diseases affecting our species, ranging from malaria and cholera to HIV, could teach us much about those diseases.

In summary: there is ample reason to be very pessimistic about the future of wild chimpanzees in west Africa. Efforts to organize a Population and Habitat Viability Assessment workshop in west Africa are being made and there will not be many more opportunities for such a project.

\section{References}

1. Gagneux, P., Woodruff. DS., Boesch, C. 1997. Furtive Female Chimpanzees, Nature 387:358-359.
2. Gagneux, P., Woodruff. DS., Boesch, C. 1997. Microsatellite Scoring errors associated with noninvasive genotyping based on nuclear DNA amplified from shed hair. Molecular Ecology 6, 861868.

3. Gagneux, P., Woodruff. DS., Boesch, C. Female reproductive strategies, paternity and community structure in a community of wild west African chimpanzees Animal Behaviour in press.

4. Takasaki H, Takenaka, O (1991) Paternity testing in chimpanzees with DNA amplification from hairs and buccal cells in wadges. A preliminary note. In: Primatology Tbday: Proceedings of the 13th Congress of the International Primatological Society. (eds. Ehara A, Kinura T, Takenaka O, Iwamoto M), pp. 613-616. Elsevier, Amsterdam.

5. Morin P.A., Woodruff, D.S., 1996. Non invasive genotyping for vertebrate conservation. In: Molecular Genetic Approaches in Conservation (eds Smith TB, Wayne RK). Oxford: Oxford University Press. pp. 298-313

6. Mundy, N.I., Winchell,C.S., Woodruff, D.S. 1997. Genetic differences between the endangered San Clemente Island loggerhead shrike Lanius ludovicianus mearnsi and two neighbouring subspecies demonstrated by mtDNA control region and cytochrome $b$ sequence variation. Molecular Ecology 6, 29-37

7. Marchesi, P., Marchesi, N., Fruth, B., Boesch, C. 1995. Census and distribution of chimpanzees in Ivory Coast. Primates,4, 591-607

8. Moore, J.J. 1985. Chimpanzee Survey in Mali, West Africa. Primate Conservation 6. 59-63.

9. Morin PA, Moore JJ, Chakraborty R, Jin L, Goodall J, Woodruff DS (1994a) Kin selection, social structure, gene flow, and the evolution of chimpanzees. Science 265, 1193-1201.

10. Goldberg, T.L., Ruvolo, M. 1997. Molecular phylogenetics and historical biogeography of east African chimpanzees. Biol. J. Linnean Soc. 61, 301324.

11. Gonder, M.K., Oates, J.F., Disotell, T.R., Forstner, M.R.J., Morales, J.C., Melnick, D.J. 1997. A new west African chimpanzee subspecies. Nature, 388, 337

12. Georges-Courbot, M-C., Sanchez, A., Lu CY. et al 1997. Isolation and Phylogenetic Characteriztion of Ebola Viruses Causing Different Outbreaks in Gabon. Emerging Infectious Diseases 3, National 
Center for Infectious Diseases, Center for Disease

Control and Prevention, Atlanta CA.

URL://www.cdc.goc/ncidod/vol3no1/courbot2.htm.

13. Huffman, M.A.; Wrangham, R.W. 1994. The diversity of medicinal plant use by chimpanzees in the wild. In: Chimpanzee Cultures, Harvard University Press,

Cambridge, Massachusetts, pp. 129-148 